\title{
Considering Careers beyond Academia: Advice for Graduate Students
}

Abraham F. Lowenthal, University of Southern California, Los Angeles

\section{ABSTRACT The author draws upon his experience and observations outside academia to provide ten suggestions for graduate students in political science who are exploring nonacademic career options. Their mentors may also find this advice useful.}

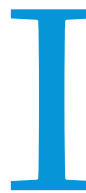
have often been asked by individual graduate students at the University of Southern California and elsewhere about how to explore career options beyond academia in a period when opportunities for tenure-track teaching positions are scarce.

Every individual case is different, of course, but over time I have come to believe that a few general points provide sound advice for most people.

\section{TEN SUGGESTIONS}

First, it is important not to think of careers in public affairs, business, consulting, international organizations, foundations, and nongovernmental organizations as second-best, "nonacademic" options. Try consciously to think of such careers as positive, valued, and rewarding alternative paths to use your talents, energy, and training-paths that may well offer more opportunities to do interesting things, to continue learning, and to make a practical considering alternative strategies. Understand that your choice of next step after graduate school need not be a lifetime choice. Leaning how the world works outside universities may well contribute eventually to an academic career, or to other opportunities.

Third, the best advice I ever got, from a senior mentor at a crucial decision-point in my own career, was not to make an employment decision with a primary view toward climbing a career ladder, but rather to ask myself what I would most enjoy doing for the next four to five years. As he wisely pointed out, future prospective employers most want to know how well you did at whatever job you had, not what job you chose. I have followed his advice throughout my life, changing positions every few years to move to something I was more interested in doing. I am still following that advice today. And I always find that work I do in one sphere contributes to my work in another.

Fourth, appreciate the fact that most opportunities in life, professional and personal, arise from serendipity, and that ser-

\section{Third, the best advice I ever got, from a senior mentor at a crucial decision-point in my own career, was not to make an employment decision with a primary view toward climbing a career ladder, but rather to ask myself what I would most enjoy doing for the next four to} five years.

difference in the world than most academic positions do. Change your mind-set from a reluctant consideration of undesirable fallback positions to an open-minded exploration of career paths worth comparing with available academic opportunities.

Second, in considering this advice, be aware that it may well differ from the advice you receive from most of your professors. Long ago they chose academia as their career; they are comfortable and feel rewarded in the university setting; and they often lack experience, even understanding or imagination, of the world beyond the campus. Many will tell you to get started as soon as possible on the academic ladder, even at a place you do not want to be, so that you can begin to climb. Be self-confident about

Abraham F. Lowenthal is professor emeritus in the School of International Relations at the University of Southern California. He has also been director of studies at the Council on Foreign Relations, founding director of both the Latin American Program at the Woodrow Wilson Center and of the Inter-American Dialogue, and founding president of the Pacific Council on International Policy. He can be reached at afl@usc.edu. endipity happens to those who are prepared for it, who are alert and open to opportunity and adept at grasping it when it appears. Prepare yourself intellectually and emotionally to be imaginative and to take risks, carefully exploring their nature before plowing full-steam ahead.

Fifth, undertake a serious, probing, and honest self-appraisal, focusing on what you most enjoy doing and also on what the outside world tells you that you are best at. Often, indeed usually, these will coincide, which makes the next steps easier.

Sixth, with your personal profile of favorite activities and strongest aptitudes clearly in mind, do some thinking, perhaps with the help of a mentor, about what kinds of jobs might fit your personal profile. Don't try to be excessively specific too early, but narrow your search to a manageable field or two rather than thinking of yourself as "open to all options." I always think about deep-sea fishing. If you know what you want to catch, the captain will take you to where those fish are most likely to be. If you say you are open to anything, he may troll aimlessly without a 
clear signal that will get you near any fish! Fish for the species you want to catch!

Seventh, to help guide your search, try to identify people who have jobs you would love to have and learn how they ended up with these attractive posts. You will learn that there are multiple paths, no one clear road, but learning about these paths may inspire and encourage you.

Eighth, there are a few things you can do to increase your chances:

- Learn to write clear, direct, active, energetic and focused prose. Sadly, this may require unlearning some bad habits you have acquired in the past few years. Read and internalize George Orwell's classic essay, "Politics and the English need to understand how to build a bridge to activities beyond taking and then teaching courses. Whatever you learn in these new areas, whatever aptitudes you develop and showcase, will help you no matter where you end up, including academia.

Ninth, invest some time thinking through how to build connections between yourself and the fields in which you would like to explore career options. Read specialized journals in the fields you want to explore, attend professional meetings, and use your institution's placement and alumni resources to meet people with relevant experience. Take internships, build networks, seek and earn the help of mentors, write memoranda or blog entries on relevant issues, do voluntary work that relates to your interests, and distinguish yourself from others by the quality and creativity of your self-assigned projects.

\section{If you know what you want to catch, the captain will take you to where those fish are most likely to be. If you say you are open to anything, he may troll aimlessly without a clear signal that will get you near any fish! Fish for the species you want to catch!}

\begin{abstract}
Language," easily accessible online. Read the best articles in Foreign Affairs, the Atlantic, and other such journals. Understand that clear, concise, and precise expression is highly valued outside academia, and that those who express themselves clearly are appreciated and rewarded.

- Develop a reputation for getting things done beyond your academic assignments, for knowing how to set and achieve goals, and how to mobilize others to achieve those goals. These, too, are qualities that society needs and rewards.
\end{abstract}

Both of these tips may require you to invest time in activities you have not needed to emphasize to get good grades in courses. You
Tenth, be persistent. Keep plugging. Write the extra letter (and learn how to write effective letters.) Make the extra call. Take the extra trip. Ask the extra question. Keep alert. Ask yourself every day what surprised you and why. Make it a habit. Don't be too obnoxious in marketing yourself, of course, but don't be too reticent.

Remember what the famous sage, Rabbi Hillel, said:

If I am for myself alone, what am I?

But if I am not for myself, who will be?

And if not now, when? 